\title{
END MILLS WITH PCD INSERTS INCLUDING INTEGRAL CHIP BREAKER
}

ALES POLZER, LUBOS KREHLIK, TOMAS TRCKA

Brno University of Technology, Faculty of Mechanical Engineering, Institute of Manufacturing Technology, Brno,

Czech Republic

DOI: 10.17973/MMSJ.2019_03_2018134

e-mail: polzer@fme.vutbr.cz

Diamond - the chemically metastable form of carbon at room temperature and standard atmospheric pressure - has become the standard material used for cutting tools. Its specific cutting properties also correspond to its difficult machinability, making it one of the most difficult-to-machine materials. With regard to this, the optimal processing technology, sharpening parameters, soldering conditions as well as tool geometry are still researching and developing. Tool geometry is a complex term, which is also affected by the integral chip breaker. In the case of polycrystalline diamond (PCD), this element is produced optimally only by the laser technology, which was used in this experiment, both for machining of an integral chip breaker and sharpening of the cutting edge. After the designing and manufacturing of the tools, measurements of the end mills were carried out. This experiment itself compared the tool geometry with and without the chip breaker from the point of view of the force loading measured by the piezoelectric dynamometer Kistler 9257B. The workpiece material was alloy EN AW 6061 and EN AW 6082.

PCD, chip breaker, force loading, EN AW 6061, EN AW 6082

\section{KEYWORDS}

\section{INTRODUCTION}

In addition to other materials, aluminium alloys are increasingly used in the automotive, aerospace and shipping industry, due to reducing the weight of components [Borovan 2006] [Fraga da Silva 2017] [Soares 2017] [Wang T. 2015] [Wang Y. 2013]. Machining of such materials, the polycrystalline diamond which belongs to the super-hard cutting materials, is widely applied [Fraga da Silva 2017] [Soares 2017] [Wang Y. 2013]. [Weinert 1993] found out that a PCD tool with cutting speed $\left(\mathbf{v}_{\mathbf{c}}\right)$ $500 \mathrm{~m} / \mathrm{min}$ obtained smaller wear than using cemented carbide with $\mathbf{v}_{\mathbf{c}} 100 \mathrm{~m} / \mathrm{min}$ when machining of metal matrix composites. [Huang 2012] focused on the machining of SiCp/Al composites using TiC-based Cermet and PCD. [Rajkumar 2018] concluded that the PCD inserts are more advised than $C B N$ for machining of aluminium based composites.

PCD (produced by HPHT) blank includes cemented tungsten carbide substrate, which provides cobalt as a binder during sintering [Elementsix 2017] [Halpin 2015]. The presence of cobalt in PCD makes this material electrically conductive. This allows machining of PCD by electrical technology. In the past, PCD sharpening was possible either by grinding or using electrical technology. However, these technologies do not allow the optimal manufacturing of the integral chip breaker on the face of PCD segment, since the manufacturing is complicated compared to the production of the chip breaker in the insert of cemented tungsten carbide [Borovan 2006] [Fraga da Silva 2017] [Soares 2017]. This has been possible with the application of laser technology in machining [Borovan 2006] [Hofmeister 2017] [Soares 2017]. The light energy is transformed into thermal energy. Acting high-energy laser beam converts the solid state into gaseous, so-called cold ablation [Borovan 2006] [Hofmeister 2017]. A small value of pulse durations in picoseconds minimizes the heating/residual damage on the surrounding material. The high value of repetition rate of the laser corresponds to the large material removal [Borovan 2006] [Zeman 2017].

The subject of the presented experiment are two end mills with brazed PCD inserts including a different integral chip breaker and an end mill with an insert without a chip breaker. The evaluation of the experiment is based on the measuring of the cutting forces at 4 levels of feed per tooth $\left(\mathbf{f}_{\mathbf{z}}\right)$ while machining of two aluminium alloys - EN AW 6061 and EN AW 6082.

Many studies have been focused on the tool and workpiece material. [Soares 2017] dealt with 3 inserts, where two of them had an integral chip breaker. The experiment investigated the influence of each inserts, cutting conditions on cutting forces and power, the chip shape according to standard ISO 3685, and others when turning aluminium alloy AlSi9Cu3. In case of CB2 insert, continuous chips were created at a small value of feed speed, which is not required [Hofmeister 2017]. Therefore, it is necessary to select the correctly range of cutting parameter for each insert. The obtained results are applicable only to these inserts of given shapes. [Fraga da Silva 2017] also investigated the influence of cutting parameters on the force loading and chip morphology during machining of AISi9Cu3 using PCD tool with and without a chip breaker. Experimental and simulation results were compared. [Wang T. 2015] focused on the optimal cutting parameters and the suitable size of PCD grains while milling of $\mathrm{SiCp} / \mathrm{Al}$ composite. Milling speed has a greater effect on the tool life than feed rate. [Muthukrishnan 2008] also conducted an experiment at various cutting parameters using different grades of PCD inserts while machining of $\mathrm{Al}-\mathrm{SiC}$ composite.

Problems with continuous chips do not occur during milling, however in many cases it is advisable to reduce the cutting forces due to the required quality of the machined surface, dimensional accuracy, etc. - for example in thin-walled parts [Borovan 2006] [Hofmeister 2017]. Another limiting factor of the resulting machining quality is the temperature in the cutting zone. Not only these parameters can be influenced by the chip breaker, hence this study is dedicated to this entity when milling. A suitable combination of a chip breaker and cooling can increase the tool life by more than $30 \%$ [Zeman 2017].

\section{DESIGN AND CONSTRUCTION}

Three right-hand and two-toothed end mills with brazed inserts were designed. The tool body material was selected CTS20D sintered carbide, which is more rigid than steel. PCD blanks are mainly manufactured in the form of circular flat plates and therefore the production of a cutting edge with constant tool cutting edge inclination $\left(\boldsymbol{\lambda}_{\boldsymbol{s}}\right)$ is not possible from this blank. The tools were designed with an average value of $\lambda_{s} 5^{\circ}$, which provides a continuous milling - see Fig. 3 . The tool side rake $(\mathbf{V f})$ has the value of $7^{\circ}$ on the tool minor cutting edge. Due to the flat face it is a variable. Its value is increasing with increasing distance from the minor cutting edge. Tools are designed with an internal tool cooling for efficient heat dissipation, more suitable chip formation, and cutting force reduction.

All tools have the same geometry of body and position of grinding seats. The individual cutters differ only by macrogeometry on the face of the inserts [Hofmeister 2017] integral chip breaker. The cutting tool labelled as RHE-0351-0, 
is designed without the chip breaker - see Fig. 1. The face of the insert is formed by a flat surface of the PCD segment and the rake angles are defined only by the position of the seat in the tool body.

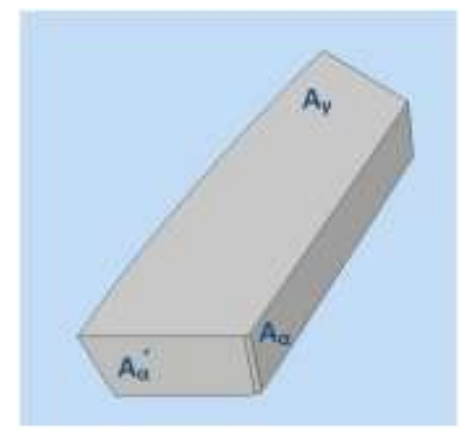

Figure 1. PCD segment - tool RHE-0351-0

Tools RHE-0351-1 and RHE-0351-2 are designed with the integral chip breaker - Fig. 2, which creates a chip breaker land width of $0.04 \mathrm{~mm}$ on major and minor cutting edges. These chip breakers are designed for laser production. RHE-0351-1 has a groove shape that creates a positive tool rake. The tool rake with respect to the insert has a constant value of $20^{\circ}$. Together with tool body geometry, the $\lambda_{s}$ on the minor cutting edge has a value of $25^{\circ}$ and the $\gamma_{f}$ is increasing from $27^{\circ}$.

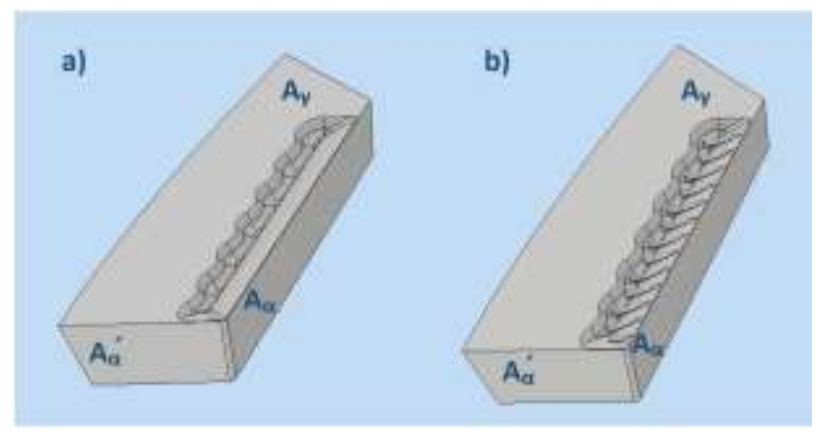

Figure 2. PCD segments a) tool RHE-0351-1, b) tool RHE-0351-2

The chip breaker of the tool RHE-0351-2 is designed with 3D shapes that create a variable tool rake. The basic shape identical to the RHE-0351-1 - is added by the 3D elements drops. The tool rake of this PCD segment is in the range of $13^{\circ}-20^{\circ}$. 3D drops are designed to reduce cutting forces in combination with cutting fluid. The aim is to create a space between the face and the leaving chip to be filled with fluid. Cutting fluid subsequently increases the volume due to the heat generated in the cutting zone to create a sliding surface, thereby reducing the chip friction on the face of the insert and the related cutting force.

In the case of end mills with a chip breaker, these are cutting tools with very positive geometry of the cutting edge. Tool side clearance $\left(\boldsymbol{\alpha}_{\mathrm{f}}\right)$ is $11^{\circ}$ for all tools. Cutting material is PCD - sort CTM302, which is characterized by a combination of diamond grain sizes in the range of 2-30 $\mu \mathrm{m}$. It has been developed for machining of aluminium alloys [Elementsix 2017].

\section{PROTOTYPE PRODUCTION}

The prototype PCD mills were produced by Rotana a.s. Tool bodies were produced on 5-axis CNC grinding machine. An important operation of the production of the milling body was manufacturing of channels for supplying of cutting fluid, which were produced by EDM sinking. Laser technology was chosen for preparation and sharpening of PCD segments, which is characterized by high precision with minimal damage on the surrounding material. Segments were cut from the circular blank using the machine Laser Pluss. Cutting of the PCD segment was performed on individual layers with $0.08 \mathrm{~mm}$ increments in the $\mathbf{z}$ axis. The soldering process was carried out in a vacuum soldering furnace, which ensures a quality and strong joint through the controlled soldering process - see Fig. 3, since it has to transfer the force loading and heat between the insert and the tool body. Silver-based solder is used when soldering non-metallic materials.

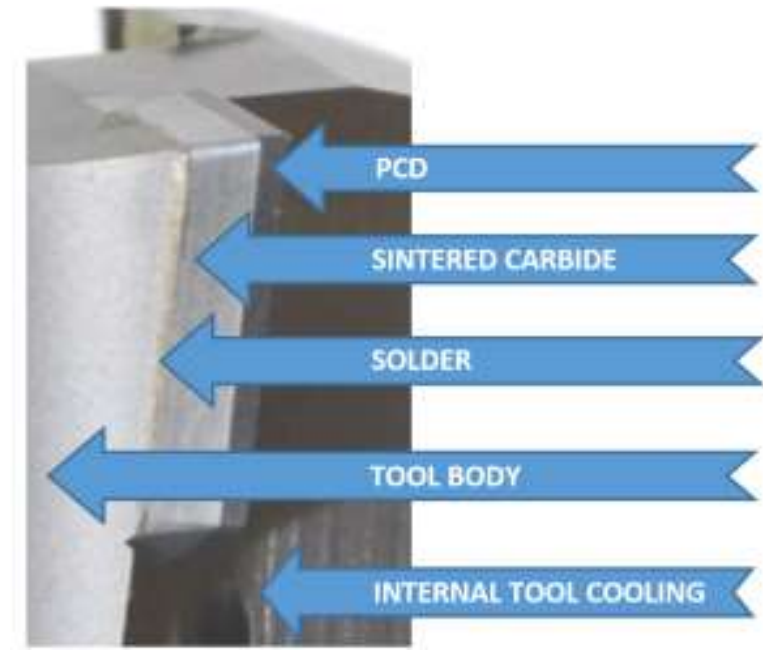

Figure 3. Interface of individual materials of the tool

Sharpening was done using laser technology as well as cutting of the PCD segments. Machine EWAG Laser Line Ultra was used for this operation. Sharpening was also carried out on individual layers. Processing parameters for machining in the PCD layer were used for keeping high precision and minimization of damage on the surrounding material in the edge area, while parameters for higher productivity were used when machining the cemented tungsten carbide substrate. All tools were manufactured under the same process conditions. Therefore, a comparable quality of sharpening can be expected.

\section{INSPECTION OF MANUFACTURED TOOLS}

Inspections of the manufactured prototypes were performed by Zoller hobCheck optical measuring device and the Alicona optical microscope. Firstly, the main dimensions of the cutting tools were checked - the value of diameter of the cutting tool (D), the corner radius $\left(r_{\varepsilon}\right)$ and the circumferential radial runout (c). These values are shown in Tab. 1.

\begin{tabular}{|c|c|c|c|}
\hline $\begin{array}{c}\text { prescribed } \\
\text { values }\end{array}$ & 0.100 & $\begin{array}{c}12.000 \pm \\
0,050\end{array}$ & 0.010 \\
\hline$R H E-0351-0$ & 0.096 & 12.004 & 0.002 \\
\hline$R H E-0351-1$ & 0.098 & 11,999 & 0.003 \\
\hline$R H E-0351-2$ & 0.099 & 12,004 & 0.003 \\
\hline
\end{tabular}

Table 1. The main measured dimensions

The tool side rake $\left(v_{f}\right)$ was measured only for the tool labelled as RHE-0351-0 tool, since for the other tools $\boldsymbol{y}_{\mathrm{f}}$ is created by a combination of body geometry and an integral chip breaker. As it has been mentioned, the value of the tool side rake value 
is variable. For this reason, this angle is measured at two distances from the minor cutting edge - see Tab. 2.

The angle $\boldsymbol{\alpha}_{\mathrm{f}}$ was measured with a value of $10.72^{\circ}$.

\begin{tabular}{|c|c|c|}
\hline & $\begin{array}{c}\mathbf{V}_{\mathrm{f}}-1 \mathrm{~mm} \text { from the } \\
\text { minor cutting edge } \\
{\left[{ }^{\circ}\right]}\end{array}$ & $\begin{array}{c}\boldsymbol{V}_{\mathrm{f}}-5 \mathrm{~mm} \text { from the } \\
\text { minor cutting edge } \\
{\left[{ }^{\circ}\right]}\end{array}$ \\
\hline$R H E-0351-0$ & 7.12 & 10.74 \\
\hline
\end{tabular}

Table 2. Tool side rake

Subsequent measurement was carried out using the Alicona InfiniteFocus measuring device. Fig. 4 shows the chip breaker of tool RHE-0351-1 and Fig. 5 represents an image of the RHE-0351-2 chip breaker.

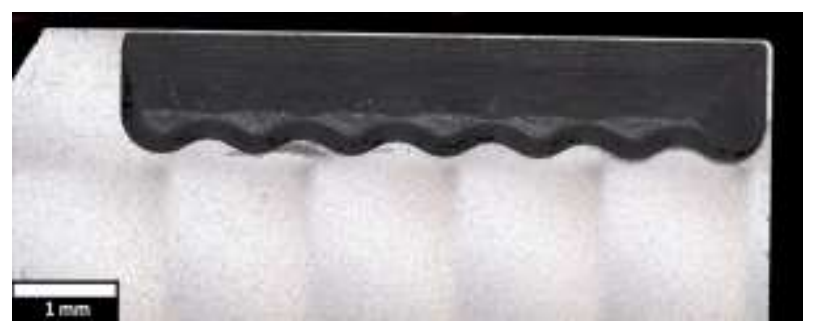

Figure 4. Image of chip breaker - tool labelled as RHE-0351-1

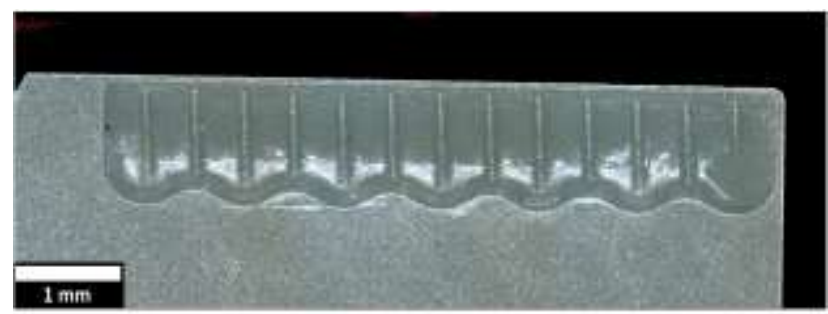

Figure 5. Image of chip breaker - tool labelled as RHE-0351-2

Firstly, rounded cutting edge radius $r_{n}$ was measured. Values of radius are in units of $\mu \mathrm{m}$. The specific radius values are shown in Tab. 3.

\begin{tabular}{|l|c|c|}
\hline & $\begin{array}{c}\text { tool major } \\
\text { cutting edge } \\
{[\mu \mathrm{m}]}\end{array}$ & $\begin{array}{c}\text { tool minor } \\
\text { cutting edge } \\
{[\mu \mathrm{m}]}\end{array}$ \\
\hline RHE-0351-0 & 7.6 & 3.8 \\
\hline RHE-0351-1 & 6.5 & 4.9 \\
\hline RHE-0351-2 & 6.3 & 5.3 \\
\hline
\end{tabular}

Table 3. Rounded cutting edge radius

Chip breaker land width $\mathbf{d}_{\mathrm{Bn}}$ (width of the facet on the face) and tool rake with respect to the insert were also measured on tools RHE-0351-1 and RHE-0351-2. These are characteristic dimensions created by the production of chip breakers. For RHE-0351-2, the measurement was carried out in places with minimum and maximum values, as these values are variable depending on the shape of the 3D elements - drops. The measured values correspond to the model (see chapter 2) and are shown in Tab. 4.

\begin{tabular}{|c|c|c|}
\hline & $\begin{array}{c}\mathbf{d}_{\mathrm{Bn}} \\
{[\mathrm{mm}]}\end{array}$ & $\begin{array}{c}\text { tool } \\
\text { rake } \\
{\left[{ }^{\circ}\right]}\end{array}$ \\
\hline$R H E-0351-1$ & 0.0483 & 20.5 \\
\hline
\end{tabular}

\begin{tabular}{|c|c|c|}
\hline $\begin{array}{c}\text { RHE-0351-2 } \\
\text { - max value }\end{array}$ & 0.0340 & 20.1 \\
\hline RHE-0351-2 & 0.0366 & 13.1 \\
\hline - min value & & \\
\hline
\end{tabular}

Table 4. Characteristics parameters of chip breakers

\section{MEASUREMENT OF FORCE LOADING}

The measurement of cutting forces acting during the milling of Al alloys destined for the aerospace industry was the aim of the experiment of prototype tools. Two Al alloys were selected, the designation system of which is shown in Tab. 5 .

\begin{tabular}{|c|c|c|}
\hline $\begin{array}{c}\text { Number of } \\
\text { workpieces }\end{array}$ & EN AW & DIN \\
\hline 1 & $6061-T 651$ & AlMg1SiCu \\
\hline 2 & $6082-\mathrm{T651}$ & AIMgSi1 \\
\hline
\end{tabular}

Table 5. Designation system of AL alloys

The machining was conducted on the vertical CNC milling machine MCV 1210 - TAJMAC-ZPS. The Kistler 9257B stationary dynamometer was used to measure the force loading. Workpiece clamping via the machine vice can be seen in Fig. 6 .

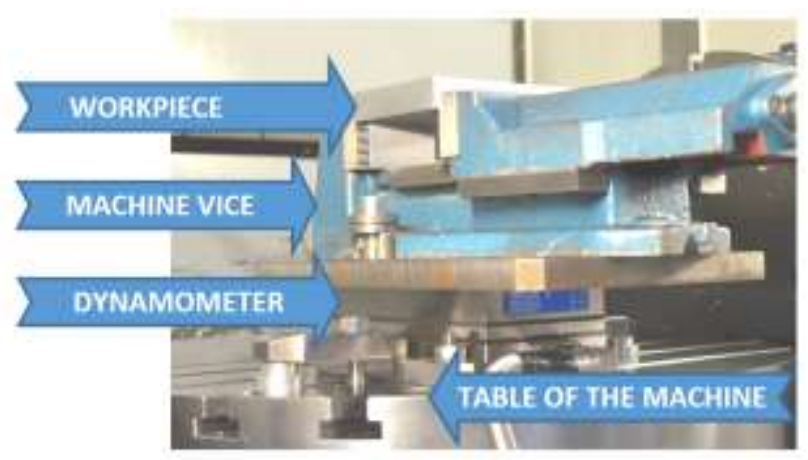

Figure 6. Setting for Measurement

Cutting conditions were based on the design of cutting tools and the application of Al alloy - see Tab. 6.

\begin{tabular}{|l|c|c|c|}
\hline \multicolumn{2}{|l|}{ Quantity } & Value & Unit \\
\hline $\begin{array}{l}\text { Revolutions of } \\
\text { the spindle }\end{array}$ & $\mathrm{n}$ & 15000 & $\mathrm{~min}^{-1}$ \\
\hline $\begin{array}{l}\text { Cutting speed } \\
\text { cut }\end{array}$ & $v_{c}$ & 565.5 & $\mathrm{~m} \cdot \mathrm{min}^{-1}$ \\
\hline $\begin{array}{l}\text { Radial depth of } \\
\text { the cut }\end{array}$ & $\mathrm{a}_{\mathrm{p}}$ & 5 & $\mathrm{~mm}$ \\
\hline
\end{tabular}

Table 6. Cutting conditions

A force load recording was performed on a workpiece of $130 \mathrm{~mm}$ length. Four $\mathbf{f}_{\mathbf{z}}$ values have been proposed for evaluating of the effect of the chip breakers on the value of force loading, since the feed speed $\mathbf{v}_{\mathbf{f}}$ has a significant effect on a chip formation. The measurement had a growing character, with higher $\mathbf{f}_{\mathbf{z}}$ values being set after each pass. This measurement was repeated for each of the three tools and 
both machined materials. Thus, 24 measurements were obtained from the experiment in total. The set values of feed per tooth (respectively $\mathbf{v}_{\mathbf{f}}$ ) are shown in Tab. 7.

\begin{tabular}{|c|c|c|}
\hline \multicolumn{1}{|l|}{ levels } & $\mathbf{f}_{\mathbf{z}}[\mathrm{mm}]$ & $\mathbf{v}_{\mathbf{f}}\left[\mathrm{mm} \cdot \mathrm{min}^{-1}\right]$ \\
\hline 1 & 0.08 & 2400 \\
\hline 2 & 0.12 & 3600 \\
\hline 3 & 0.16 & 4800 \\
\hline 4 & 0.20 & 6000 \\
\hline
\end{tabular}

Table 7. Values of feed speed

Fig. 7 shows a schematic view of the clamping of the end mill/workpiece including a partially machined workpiece.

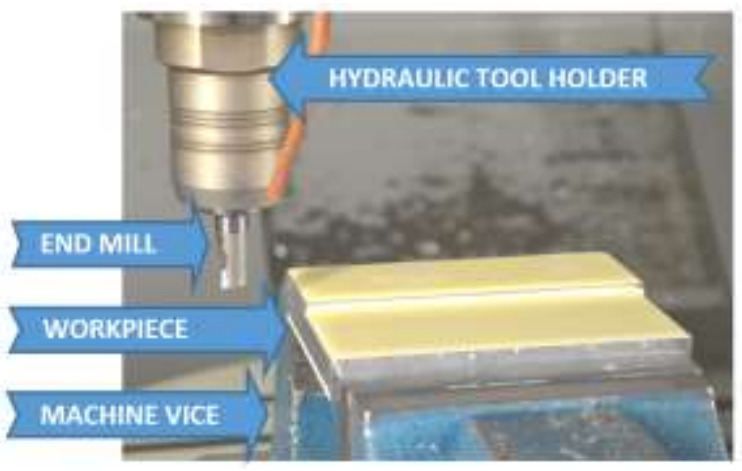

Figure 7. Schema of machining process

\section{EVALUATION}

OF

FORCE

LOADING

Measured data was evaluated using software Microsoft Excel. With this software, raw data filtering exported from software DynoWare was first performed. Maximum values from each revolution of the spindle were selected for the evaluation of the total force exerted by a cutting part $(\mathbf{F})$. Then diagrams were created from the filtered data, which show the total cutting force depending on the tool and the machined materials. In the left part of the diagram are box plots for alloy EN AW 6061-T651, while in the right are box plots for alloy EN AW 6082-T651.

In Fig. 8 are shown the total forces for $\mathbf{f}_{\mathbf{z}}$ of the value of 0.08 $\mathrm{mm}$. The diagram shows a decrease in force of the RHE-0351-1 tool during machining of alloy 6061-T651. The cutting force is reduced due to sharper cutting edge geometry. The RHE-0351-2 tool (with a 3D chip breaker) shows an increase in the total force exerted by a cutting part. This is due to the increased interface between the chip and the face of the insert. On the other hand, when machining of the 6082-T651 alloy with a 3D chip breaker, the total force is reduced.

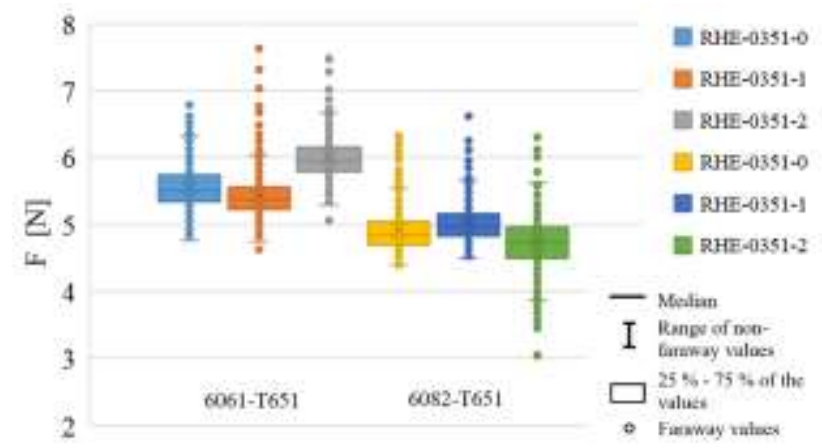

Figure 8. Graph of total force exerted by a cutting part at $\mathbf{f}_{\mathbf{z}}=0.08 \mathrm{~mm}$
This force trend was found only at $\mathbf{f}_{\mathbf{z}} 0.08 \mathrm{~mm}$ and material 6082-T651, which was most likely due to the very small chip thickness and low loading on the cutting wedge where the cutting fluid reduced the friction. The same total force trend was shown for the following values of feed per tooth from Tab. 7 - see Fig. 9, 10, 11. Geometry of the tool RHE-0351-1 reduced the force relative to the RHE-0351-O with a polished face in all of the following cases. Then, the increase of the total force of the RHE-0351-2 tool with a 3D chip breaker is noticeable.

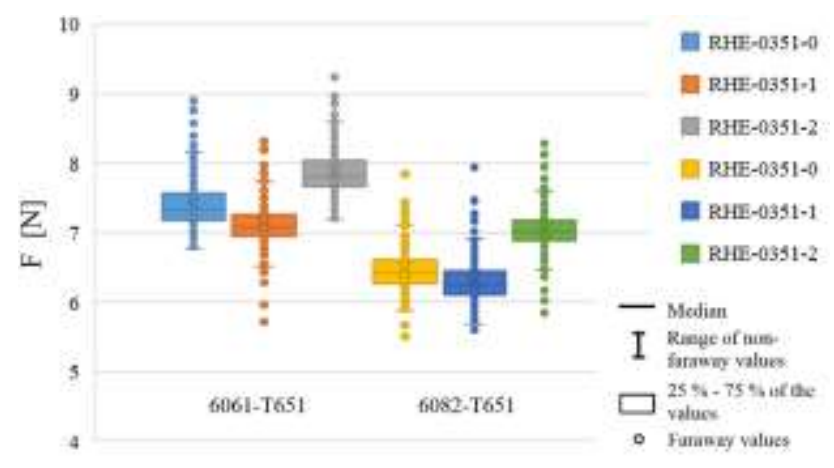

Figure 9. Graph of total force exerted by a cutting part at $f_{z}=0.12 \mathrm{~mm}$

Values of total force depending on the increasing feed speed have a growing character, which corresponds to the increasing cross-section of the chip.

From these dependencies can be seen that higher forces were achieved when machining of the 6061-T651 alloy compared to the 6082-T651.

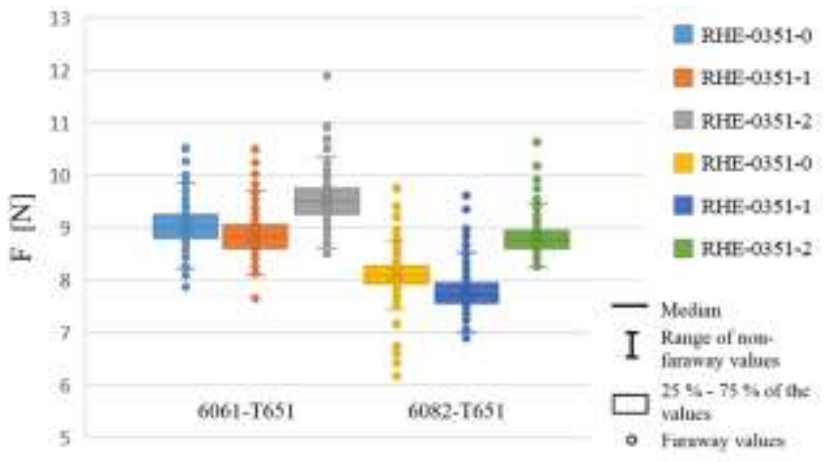

Figure 10. Graph of total force exerted by a cutting part at $f_{z}=0.16 \mathrm{~mm}$

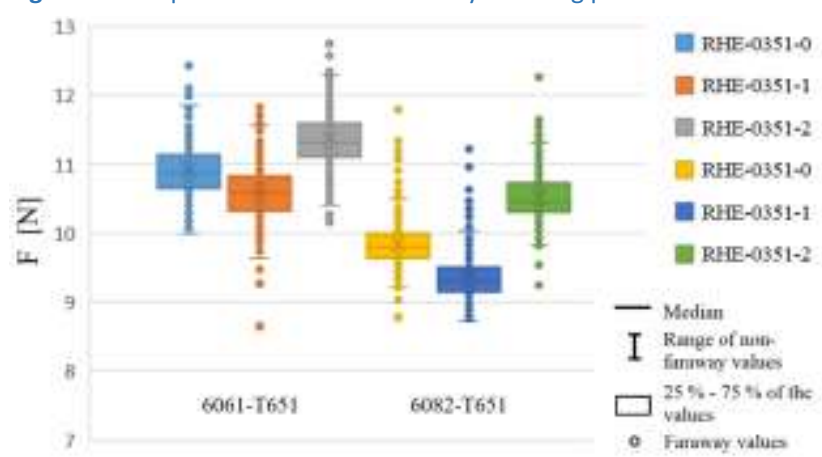

Figure 11. Graph of total force exerted by a cutting part at $\mathrm{f}_{\mathrm{z}}=0.20 \mathrm{~mm}$

The total cutting forces evaluated from the equation (1) had the same trend as the $\mathbf{F}_{\mathbf{x y}}$ force resultant in all cases, since the $\mathbf{F}_{\mathbf{p}}$ force acting at the $\mathbf{z}$ axis reached very small values and did not change the trend of the achieved results. The median of $\mathbf{F}_{\mathbf{p}}$ reaches the maximum value of $2.02 \mathrm{~N}$ for the RHE-0351-2. For this force component, the lowest value for the RHE-0351-0, then the RHE-0351-1 and the highest value for the RHE-0351-2 was measured. The RHE-0351-O has only a lapped face and the RHE-0351-2 has protrusions (drops) that slowed the chip 
flowing in the axial direction - in the direction of the tool cutting edge inclination $\left(\boldsymbol{\lambda}_{\mathbf{s}}\right)$.

$$
F=\sqrt{F_{x}^{2}+F_{y}^{2}+F_{p}^{2}}=\sqrt{F_{x y}^{2}+F_{p}^{2}}
$$

\section{CONCLUSION}

Laser technology was used for sharpening and preparation of inserts, which is suitable for machining super-hard cutting materials with 3D macro-geometry of inserts.

During the short-time experiment with which the prototype tools were subjected, the influence of the geometry of the cutting edge on the value of total force was confirmed.

The same trend of the total force exerted by a cutting part for $\mathbf{f}_{\mathbf{z}}$ higher than $0.08 \mathrm{~mm}$ is noticeable from the stated results. With these parameters, the decrease in total force was achieved for the tool labelled as RHE-0351-1, where the given chip breaker caused more positive geometry of the tool. On the contrary, the increase in the force was observed with the RHE-0351-2 tool, where the designed 3D chip breaker proved to be an inappropriate element for decreasing cutting forces. 3D drops on the face of the chip breaker caused an increase in the interface between the chip and the tool (friction), thus increasing the cutting force during machining of the given workpiece materials, which achieve higher plasticity and lower mechanical properties compared to steel, titanium and other.

Lower cutting forces result in a decrease of the cutting edge loading at higher feed speeds, which can be used for a higher value of feed per tooth or high productivity machining. The face facet contributes to the higher strength of the cutting edge.

Higher forces were achieved when machining of the 6061-T651 alloy compared to the 6082-T651 for all levels of feed per tooth.

\section{ACKNOWLEDGMENTS}

This article was supported and co-financed from a specific research FSI-S-16-3717 called "Research in Field of Modern Production Technologies for Specific Applications".

The results of this project NETME CENTRE PLUS (LO1202) were obtained with the financial support of the Ministry of Education, Youth and Sports under the targeted support of the "National programme of sustainability I."

\section{REFERENCES}

[Borovan 2006] Borovan, P. Laser technology moves opportunity of tools with diamond and cubic boron nitride (in Czech). Technicky tydenik [online]. 2006, 1. 1. 2006,

[23. 2. 2018]. Available from

https://www.technickytydenik.cz/rubriky/archiv/laserovetechn ologie-posouvaji-moznosti-nastroju-s-diamantem-a-kubickymnitridemboru16447.html.

[Elementsix 2017] Elementsix. Synthetic Polycrystalline Diamond (PCD). Elementsix [online]. c2017 [8. 5. 2018]. Available from https://www.e6.com/en/Home/Materials+and+products/Synth etic+Polycrystalline+Diamond+\%28PCD\%29/.

[Fraga da Silva 2017] Fraga da Silva, T., Soares, R. B., Jesus, A. M. P., Rosa, P. A. R. and Reis, A. Simulation Studies of Turning of Aluminium Cast Alloy Using PCD Tools. Procedia CIRP, 2017, Vol.58, pp 555-560. ISSN 2212-8271.
[Halpin 2015] Halpin, T. and Haas-Wittmüss, J. Special synthetic diamond for machining (in Czech). MM Prumyslove spektrum [online]. 2015, 1 [23. 2. 2018]. Available from https://www.mmspektrum.com/clanek/specialnisyntetickydiamant-urceny-pro-obrabeni.html.

[Hofmeister 2017] Hofmeister. Adapting of chip breaker on the cutting tool for specific machining conditions. MM Prumyslove spektrum [online]. 2017, 5 [30. 9. 2018]. Available from https://www.mmspektrum.com/clanek/adaptace-utvarece-nareznem-nastroji-pro-konkretni-podminky-obrabeni.html.

[Huang 2012] Huang, S. T., Zhou, L., Yu, X. L. and Cui, Y. Experimental study of high-speed milling of SiCp/Al composites with PCD tools. The International Journal of Advanced Manufacturing Technology, 2012, Vol.62, No.5-8, pp 487-493. ISSN 1433-3015.

[Muthukrishnan 2008] Muthukrishnan, N., Murugan, M. and Prahlada Rao, K. An investigation on the machinability of Al-SiC metal matrix composites using pcd inserts. The International Journal of Advanced Manufacturing Technology, 2008, Vol.38, No.5-6, pp 447-454. ISSN 1433-3015.

[Rajkumar 2018] Rajkumar, K., Nambiraj, K. M., Gnanavelbabu, A. and Sabarinathan, P. Machining characteristics evaluation of aluminium composites based on CBN and PCD inserts. Materials Today: Proceedings, 2018,

Vol.5, No.2, pp 8424-8430. ISSN 2214-7853.

[Soares 2017] Soares, R. B., P. de Jesus, A. M, Neto, R. J. L., Rosa, P. A. R., Machado, M. and Reis, A. Machinability of an Aluminium Cast Alloy Using PCD Tools for Turning. In: Materials Design and Applications, Springer, Cham, March 2017, pp 329346. ISBN 978-3-319-50784-2.

[Wang T. 2015] Wang, T., Xie, L., Wang, X. and Ding, Z. PCD tool performance in high-speed milling of high volume fraction SiCp/Al composites. The International Journal of Advanced Manufacturing Technology, June 2015, Vol.78, No.9-12, pp 1445-1453. ISSN 1433-3015.

[Wang Y. 2013] Wang, Y., Cui, X., Xu, H. and Jiang, K. Cutting force analysis in reaming of ZL102 aluminium cast alloys by PCD reamer. The International Journal of Advanced Manufacturing Technology, July 2013, Vol.67, No.5-8, pp 1509-1516. ISSN 1433-3015.

[Weinert 1993] Weinert, K. and König, W. A Consideration of Tool Wear Mechanism when Machining Metal Matrix Composites (MMC). CIRP Annals, 1993, Vol.42, No.1, pp 95-98. ISSN 0007-8506.

[Zeman 2017] Zeman, P. Research of progressive laser technologies (in Czech). MM Prumyslove spektrum [online]. 2017, 9 [29. 9. 2018]. Available from https://www.mmspektrum.com/clanek/vyzkum-progresivnichlaserovych-technologii.html. 


\section{CONTACT:}

Ing. Ales Polzer, Ph.D.

Brno University of Technology,

Faculty of Mechanical Engineering,

Institute of Manufacturing Technology,

Technicka 2896/2, 61669 Brno, Czech Republic

e-mail: polzer@fme.vutbr.cz 